\title{
White light generation controlled by changing the concentration of silver nanoparticles hosted by $\mathrm{Ho}^{3+} / \mathrm{Tm}^{3+} / \mathrm{Yb}^{3+}$ doped $\mathrm{GeO}_{2}-\mathrm{PbO}$ glasses
}

\author{
Mauricio E. Camilo a,b ${ }^{\mathrm{a}}$, Elton de O. Silva ${ }^{\mathrm{a}}$, Luciana R.P. Kassab ${ }^{\text {a }}$, José A.M. Garcia ${ }^{\mathrm{a}, \mathrm{b}}$, Cid B. de Araújo ${ }^{\mathrm{c}, *}$ \\ ${ }^{a}$ Faculdade de Tecnologia de São Paulo (FATEC-SP), CEETEPS/UNESP, São Paulo, SP, Brazil \\ ${ }^{\mathrm{b}}$ Departamento de Engenharia de Sistemas Eletrônicos, Escola Politécnica da USP, São Paulo, SP, Brazil \\ ' Departamento de Física, Universidade Federal de Pernambuco, 50670-901 Recife, PE, Brazil
}

\section{A R T I C L E I N F O}

Article history:

Received 16 February 2015

Received in revised form 15 April 2015

Accepted 17 April 2015

Available online 28 April 2015

\section{Keywords:}

Frequency upconversion

Rare-earth ions

Energy transfer

Silver nanoparticles

Germanate glass

White light generation

\begin{abstract}
A B S T R A C T
Frequency upconversion (UC) experiments were performed with $\mathrm{GeO}_{2}-\mathrm{PbO}$ glasses, containing silver nanoparticles (NPs), doped with holmium $\left(\mathrm{Ho}^{3+}\right)$, thulium $\left(\mathrm{Tm}^{3+}\right)$ and ytterbium $\left(\mathrm{Yb}^{3+}\right)$ ions. The samples were excited using a continuous-wave diode laser operating at $980 \mathrm{~nm}$. The UC intensities and the colors of the samples were controlled by changing the concentrations of the rare-earth ions (REI) and the silver NPs nucleated inside the samples. The colors observed spanned the visible range from the red-yellow to the blue. For a particular combination of silver NPs and REI concentrations it was obtained white light generation corresponding to the CIE coordinates $X=0.33$ and $Y=0.33$.
\end{abstract}

(C) 2015 Elsevier B.V. All rights reserved.

\section{Introduction}

Frequency upconversion (UC) processes in organic and inorganic materials have been largely exploited in the past decades because of their potential to convert light from the infrared to the visible [1-7]. In particular the investigation of glasses doped with rare-earth ions (REI) for possible photonic applications is still attracting large interest in the present days.

Photoluminescence (PL) is the main technique used to investigate UC processes. When the three primary colors (red-greenblue) are obtained with adjustable intensities, the color of the luminescent sample can be controlled and for a specific choice of parameters white light generation (WLG) can be obtained. Large number of experiments in this area was reported with glasses doped simultaneously with holmium $\left(\mathrm{Ho}^{3+}\right)$, thulium $\left(\mathrm{Tm}^{3+}\right)$, and ytterbium $\left(\mathrm{Yb}^{3+}\right)$ ions. For instance, in experiments where $\mathrm{Yb}^{3+}$ ions are resonantly excited, energy transfer (ET) from $\mathrm{Yb}^{3+}$ to $\mathrm{Ho}^{3+}$ and from $\mathrm{Yb}^{3+}$ to $\mathrm{Tm}^{3+}$ are responsible for the frequency upconverted PL. Green light at $545 \mathrm{~nm}$ and red emission at $658 \mathrm{~nm}$ are produced by the excited $\mathrm{Ho}^{3+}$ ions while blue emission at $477 \mathrm{~nm}$ is emitted by the excited $\mathrm{Tm}^{3+}$ ions. The CIE (Commission Internationale de ÍEclairage) chromaticity diagram is used to characterize the

\footnotetext{
* Corresponding author.

E-mail address: cid@df.ufpe.br (C.B. de Araújo).
}

samples' color. In the studies toward WLG the materials parameters are choose in order to obtain the CIE coordinates as near as possible from the white point $(X=0.33 ; Y=0.33)$. There are many reports that present reasonable results using different materials doped with $\mathrm{Ho}^{3+} / \mathrm{Tm}^{3+} / \mathrm{Yb}^{3+}$, such as aluminum-germanate glasses [8], oxyfluoride nanoglass [9], $\mathrm{SrMoO}_{4}$ nanocrystals [10], tellurite glasses [11,12] and lead-germanate glasses [13]. However to reach the white point is challenging.

In another research direction to obtain UC with large efficiency, several authors exploited the enhanced PL of REI in the presence of metallic nanoparticles (NPs). Then, the PL enhancement is due to the influence of two effects: the increase of the local field on the REI located in the proximity of the NPs and the ET from excited NPs to the REI. This procedure to obtain larger PL efficiency was demonstrated for various glass compositions doped with different REI and containing silver or gold NPs [13-19].

In particular, germanate glasses with REI and metallic NPs are good candidates for photonic applications due to their wide transmission window, from the visible to mid-infrared region, good mechanical strength, large chemical durability, low cut-off phonon energy $\left(\sim 800 \mathrm{~cm}^{-1}\right)$ and high refractive index ( $\left.\sim 2\right)$ [14]. UC processes have been studied in germanate glasses doped with $\mathrm{Eu}^{3+}$ [20,21], $\mathrm{Tm}^{3+}$ [22], $\mathrm{Er}^{3+}[23], \quad \mathrm{Er} / \mathrm{Yb}^{3+}[24], \mathrm{Tm}^{3+} / \mathrm{Yb}^{3+}$ [25], $\mathrm{Er}^{3+} / \mathrm{Tm}^{3+} / \mathrm{Yb}^{3+}$ [26] and $\mathrm{Tm}^{3+} / \mathrm{Ho}^{3+} / \mathrm{Yb}^{3+}$ [13] and $\mathrm{Nd}^{3+}$ [27]. In all references, except in Ref. [13], the samples contained silver or gold 
NPs fabricated using the melt-quenching method followed by appropriated heat-treatment of the samples.

In the present work, we analyze the influence of silver NPs on the colors emitted by $\mathrm{GeO}_{2}-\mathrm{PbO}$ glasses doped with $\mathrm{Ho}^{3+}, \mathrm{Tm}^{3+}$, and $\mathrm{Yb}^{3+}$ excited at $980 \mathrm{~nm}$ to extend the results of [13]. It is shown for the first time that the presence of silver NPs allows observation of WLG in samples whose REI concentrations, in the absence of NPs, could not enable WLG. Also, it is shown that changing the amount of silver NPs inside the $\mathrm{GeO}_{2}-\mathrm{PbO}$ glass samples doped with fixed concentrations of the rare-earth ions, allows the control of the samples' color.

\section{Experimental details}

The samples investigated were fabricated using the melt-quenching method with the starting composition: $40 \mathrm{GeO}_{2}-60 \mathrm{PbO}$. The doping species were $\mathrm{Ho}_{2} \mathrm{O}_{3}$ (0.9 and 0.65 wt.\%), $\mathrm{Tm}_{2} \mathrm{O}_{3}$ (0.60 wt.\%), $\mathrm{Yb}_{2} \mathrm{O}_{3}$ (3.2 wt.\%) and $\mathrm{AgNO}_{3}$ (1.0 wt.\% and $2.5 \mathrm{wt} . \%$ ). Two different sets of samples were prepared with the same $\mathrm{Tm}_{2} \mathrm{O}_{3}$ and $\mathrm{Yb}_{2} \mathrm{O}_{3}$ concentrations but with different concentrations of $\mathrm{Ho}_{2} \mathrm{O}_{3}$ and $\mathrm{AgNO}_{3}$; the first set includes samples without NPs studied in our previous report [13] and also samples having $1.0 \mathrm{wt} . \%$ of $\mathrm{AgNO}_{3}$. The second set have samples prepared with 0.6 wt.\% of $\mathrm{Ho}_{2} \mathrm{O}_{3}$ and 2.5 wt.\% of $\mathrm{AgNO}_{3}$, but with the same concentrations of $\mathrm{Tm}_{2} \mathrm{O}_{3}$ and $\mathrm{Yb}_{2} \mathrm{O}_{3}$ as the other set of samples.

The reagents were melted in an alumina crucible for $1 \mathrm{~h}$ at $1200^{\circ} \mathrm{C}$, quenched in a preheated brass mold, annealed at $420^{\circ} \mathrm{C}$ during $1 \mathrm{~h}$ (to avoid internal stress) and cooled to room temperature inside the furnace. After this procedure, the samples were polished and cut in order to have parallel faces with $2.0 \mathrm{~mm}$ thickness. The samples prepared with $\mathrm{AgNO}_{3}$ were submitted to heat-treatment (HT) during $12 \mathrm{~h}$ and $24 \mathrm{~h}$ at $420^{\circ} \mathrm{C}$ to thermally reduce the $\mathrm{Ag}^{+}$ions to $\mathrm{Ag}^{0}$, enabling the nucleation of silver NPs.

Although the study of the mechanisms of silver NPs formation is beyond the scope of the present article, we recall that the $\mathrm{AgNO}_{3}$ compound added to the starting glass constituents easily decompose at the temperatures used to prepare the samples by the reaction $2 \mathrm{AgNO}_{3} \rightarrow \mathrm{Ag}_{2} \mathrm{O}+2 \mathrm{NO}_{2}+\frac{1}{2} \mathrm{O}_{2}$. On the other hand, $\mathrm{Ag}_{2} \mathrm{O}$ decomposes to metallic $\mathrm{Ag}^{0}$ and to $\mathrm{O}_{2}$ through $\mathrm{Ag}_{2} \mathrm{O} \rightarrow 2 \mathrm{Ag}+\frac{1}{2} \mathrm{O}_{2}[28,29]$. Also individual silver ions produced during melting may reduce to $\mathrm{Ag}^{0}$ during the HT due to electrons extracted from atoms that are intrinsic to the glass, namely the nonbridging oxygens.

The samples containing Ag NPs, used in the experiments, were labeled as: A $\left(0.9 \% \mathrm{Ho}^{3+} ; 0.6 \% \mathrm{Tm}^{3+} ; 3.2 \% \mathrm{Yb}^{3+} ; 1.0 \% \mathrm{AgNO}_{3} ; \mathrm{HT}: 12 \mathrm{~h}\right) ; \mathrm{B}\left(0.9 \% \mathrm{Ho}^{3+} ; 0.6 \%\right.$ $\left.\mathrm{Tm}^{3+} ; 3.2 \% \mathrm{Yb}^{3+} ; 1.0 \% \mathrm{AgNO}_{3} ; \mathrm{HT}: 24 \mathrm{~h}\right) ; \mathrm{C}\left(0.65 \% \mathrm{Ho}^{3+} ; 0.6 \% \mathrm{Tm}^{3+} ; 3.2 \% \mathrm{Yb}^{3+}\right.$; $2.5 \% \mathrm{AgNO}_{3}$; $\left.\mathrm{HT}: 24 \mathrm{~h}\right) ; \mathrm{D}\left(0.65 \% \mathrm{Ho}^{3+} ; 0.6 \% \mathrm{Tm}^{3+} ; 3.2 \% \mathrm{Yb}^{3+} ; 2.5 \% \mathrm{AgNO}_{3} ; \mathrm{HT}: 12 \mathrm{~h}\right)$.

A $200 \mathrm{kV}$ transmission electron microscope (TEM) was used to determine the sizes and shapes of the silver NPs. A commercial spectrophotometer was used to measure the optical absorption spectra from 400 to $2000 \mathrm{~nm}$. The PL measurements were made by exciting the samples using a $980 \mathrm{~nm}$ continuous-wave diode laser (maximum power on the samples: $200 \mathrm{~mW}$ ). A spectrometer attached to a photomultiplier and a computer was used to analyze the PL signals.

\section{Results and discussion}

The linear absorption spectra of the samples were similar to the ones presented in [13], except for the amplitudes of the absorption peaks that depend on the REI and NPs concentrations. Fig. 1 shows the absorbance spectra for two samples doped with $\mathrm{Tm}^{3+}, \mathrm{Ho}^{3+}$, $\mathrm{Yb}^{3+}$ ions (with and without metallic NPs). The absorption transitions associated with the $\mathrm{Tm}^{3+}$ ions correspond to the bands centered at $450 \mathrm{~nm}\left({ }^{3} \mathrm{H}_{6} \rightarrow{ }^{1} \mathrm{G}_{4}\right), 680 \mathrm{~nm}\left({ }^{3} \mathrm{H}_{6} \rightarrow{ }^{3} \mathrm{~F}_{2,3}\right)$ and $800 \mathrm{~nm}$ $\left({ }^{3} \mathrm{H}_{6} \rightarrow{ }^{3} \mathrm{H}_{4}\right)$. The $\mathrm{Ho}^{3+}$ transitions are associated to the bands at $450\left({ }^{5} \mathrm{I}_{8} \rightarrow{ }^{5} \mathrm{~F}_{1}+{ }^{5} \mathrm{G}_{6}\right), 480\left({ }^{5} \mathrm{I}_{8} \rightarrow{ }^{5} \mathrm{~F}_{2}+{ }^{5} \mathrm{~F}_{3}\right), 530\left({ }^{5} \mathrm{I}_{8} \rightarrow{ }^{5} \mathrm{~F}_{4}+{ }^{5} \mathrm{~S}_{2}\right)$, $640\left({ }^{5} \mathrm{I}_{8} \rightarrow{ }^{5} \mathrm{~F}_{5}\right)$ and $930 \mathrm{~nm}\left({ }^{5} \mathrm{I}_{8} \rightarrow{ }^{5} \mathrm{I}_{5}\right)$. The absorption band at $980 \mathrm{~nm}$ corresponds to the $\mathrm{Yb}^{3+}$ ions $\left({ }^{2} \mathrm{~F}_{7 / 2} \rightarrow{ }^{2} \mathrm{~F}_{5 / 2}\right)$. The absorption spectra did not show the localized surface plasmons (LSP) band because the volume fraction occupied by the NPs is small. However the TEM images obtained for all heat-treated samples show silver NPs with average diameter of $\approx 7 \mathrm{~nm}$ but filling a small volume fraction of the samples. Energy dispersive spectroscopy (EDS) data (not shown) corroborated the $\mathrm{Ag}$ composition of the NPs. The LSP band in the range from 400 to $500 \mathrm{~nm}$ was clearly observed in $\mathrm{GeO}_{2}-\mathrm{PbO}$ glass doped with $\mathrm{Er}^{3+} / \mathrm{Tm}^{3+} / \mathrm{Yb}^{3+}$ because $4.0 \mathrm{wt}$ \% of $\mathrm{AgNO}_{3}$ was used and consequently larger amount of

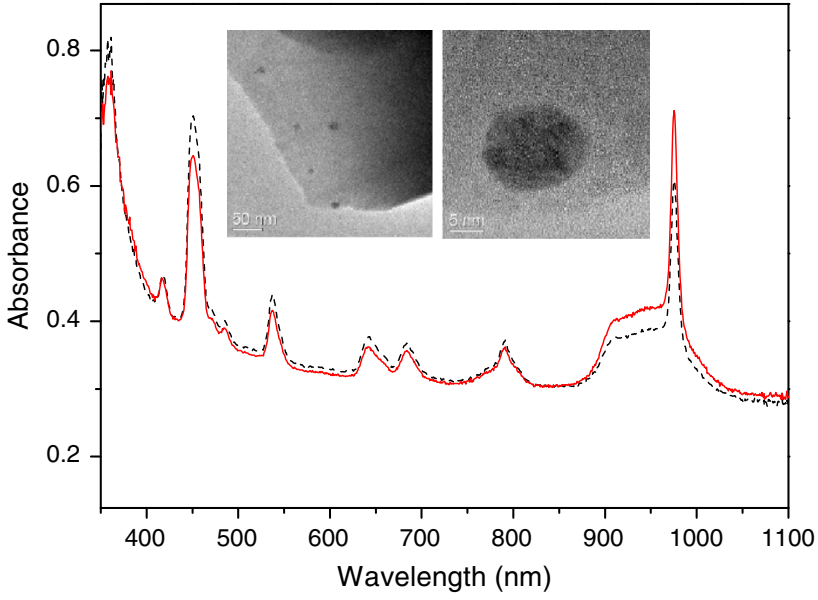

Fig. 1. Absorption spectra of the sample prepared with $2.5 \mathrm{wt} . \%$ of $\mathrm{AgNO}_{3}$. The red (black) line corresponds to the sample with Ag NPs (without NPs). The inset show images of the silver NPs nucleated in the sample. Sample thickness: $3 \mathrm{~mm}$. (For interpretation of the references to color in this figure legend, the reader is referred to the web version of this article.)

Ag NPs was nucleated [26]. The background observed in the whole spectral region is due to the rough polishing of the sample's surfaces.

Figs. 2 and 3 present the PL spectra of the samples excited at $980 \mathrm{~nm}$. The blue light at $477 \mathrm{~nm}$ is due to the emission from $\mathrm{Tm}^{3+}$ ions that corresponds to the transition ${ }^{1} \mathrm{G}_{4} \rightarrow{ }^{3} \mathrm{H}_{6}$. The green light at $545 \mathrm{~nm}$ is emitted by the $\mathrm{Ho}^{3+}$ ions, due to the transition $\left({ }^{5} \mathrm{~F}_{4} ;{ }^{5} \mathrm{~S}_{2}\right) \rightarrow{ }^{5} \mathrm{I}_{8}$. The red light at $660 \mathrm{~nm}$ has contributions of both REI and the transitions responsible for this emission are ${ }^{1} \mathrm{G}_{4} \rightarrow{ }^{3} \mathrm{~F}_{4}$ from $\mathrm{Tm}^{3+}$ and ${ }^{5} \mathrm{~F}_{5} \rightarrow{ }^{5} \mathrm{I}_{8}$ from $\mathrm{Ho}^{3+}$.

It can be observed for the samples prepared with $1.0 \mathrm{wt} . \%$ of $\mathrm{AgNO}_{3}$ (samples A and $\mathrm{B}$ ) that the amplitudes of all transitions are increased with respect to the sample without silver NPs. An enhancement of about $50 \%$ for the blue and red emissions and $113 \%$ for the green PL was obtained in sample B. On the other hand, for the samples prepared with $2.5 \mathrm{wt}$.\% of $\mathrm{AgNO}_{3}$ (samples $\mathrm{C}$ and D), a smaller PL increase is observed for the blue and red emissions while the green emission was partially quenched. This behavior is attributed to the closer proximity between the REI and the NPs in the sample with larger amount of NPs.

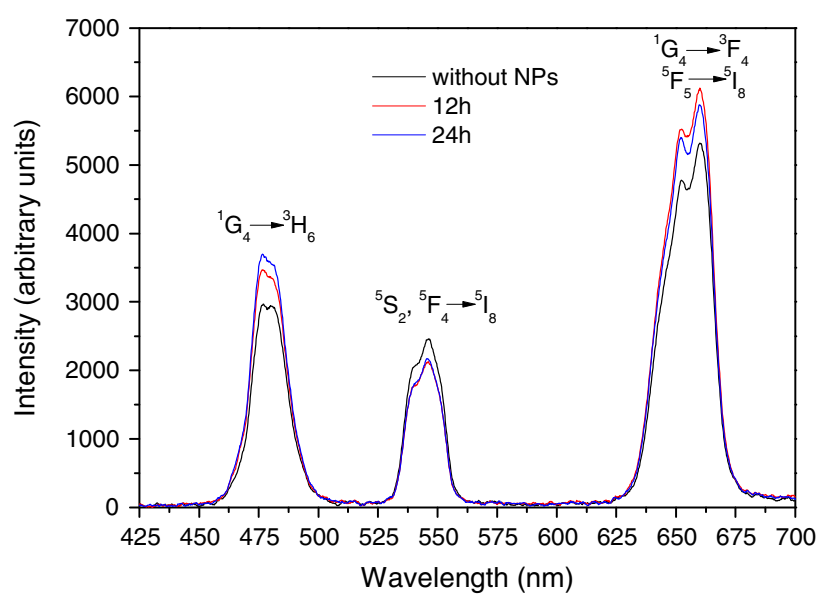

Fig. 2. Luminescence spectra of the $\mathrm{Ho}^{3+} / \mathrm{Tm}^{3+} / \mathrm{Yb}^{3+}$ doped $\mathrm{PbO}-\mathrm{GeO}_{2}$ glass prepared with $1.0 \mathrm{wt} . \%$ of $\mathrm{AgNO}_{3}$. The three curves correspond to different heattreatment times (0,12 and $24 \mathrm{~h})$. Excitation: $200 \mathrm{~mW}$ at $980 \mathrm{~nm}$. 


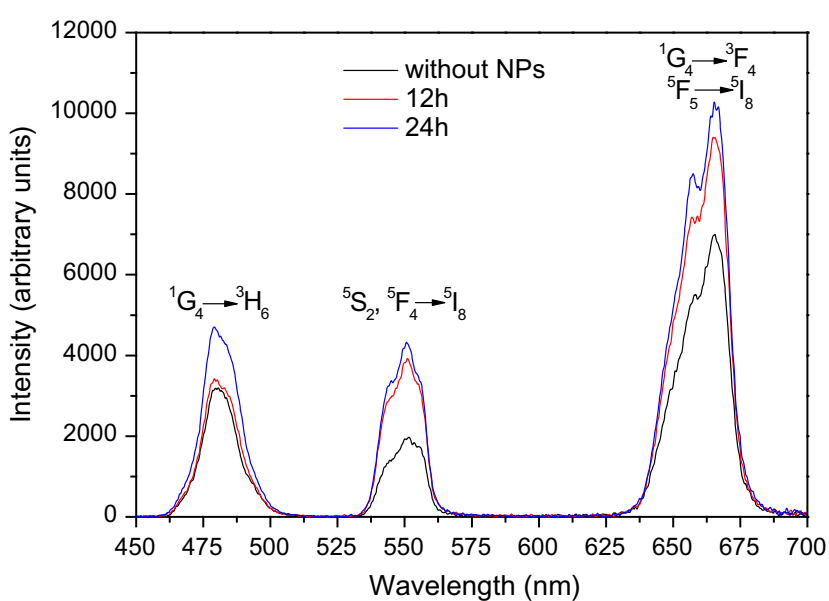

Fig. 3. Luminescence spectra of the $\mathrm{Ho}^{3+} / \mathrm{Tm}^{3+} / \mathrm{Yb}^{3+}$ doped $\mathrm{PbO}-\mathrm{GeO}_{2}$ glass prepared with $2.5 \mathrm{wt} . \%$ of $\mathrm{AgNO}_{3}$. The three curves correspond to different heattreatment times $(0,12$ and $24 \mathrm{~h})$. Excitation: $200 \mathrm{~mW}$ at $980 \mathrm{~nm}$.

In order to identify the UC pathways the PL intensity, $I_{U C}$, was measured as a function of the laser power, $P$, for each UC emission. In the absence of saturation, it is expected that $I_{U C} \propto P^{N}$ and the slope determined in the log-log plot of $I_{U C}$ versus $P$ indicates the number of photons, $N$, that participate in the UC process. Fig. 5 indicates the values of $N=2.33$ (corresponding to $477 \mathrm{~nm}$ ), 2.00 (at $545 \mathrm{~nm}$ ), and 1.54 (at $665 \mathrm{~nm}$ ) for sample B. We recall that the slopes measured for the samples prepared without silver NPs [13] were $2.47(477 \mathrm{~nm}), 1.84(545 \mathrm{~nm})$ and $1.52(665 \mathrm{~nm})$. The UC pathways proposed in the present case are the same proposed in [13] as illustrated in Fig. 4. Due to the large $\mathrm{Yb}^{3+}$ ions concentration and due to the larger cross-section of the transition ${ }^{2} \mathrm{~F}_{7 / 2} \rightarrow{ }^{2} \mathrm{~F}_{5 / 2}$ in comparison with the cross-sections of all transitions of the $\mathrm{Ho}^{3+}$ and $\mathrm{Tm}^{3+}$ ions, we attribute the efficient UC process to the ET from the excited $\mathrm{Yb}^{3+}$ ions to the $\mathrm{Ho}^{3+}$ and $\mathrm{Tm}^{3+}$ ions. The deviation from the expected slopes $(N=2$ and 3$)$ is attributed to saturation of the $\mathrm{Yb}^{3+}$ absorption transition. The results obtained for the samples A, C and D also show slopes smaller than 2 and 3, as in sample B.

Fig. 6 presents the CIE chromaticity diagram with coordinates corresponding to the emission spectra presented in Fig. 2. The

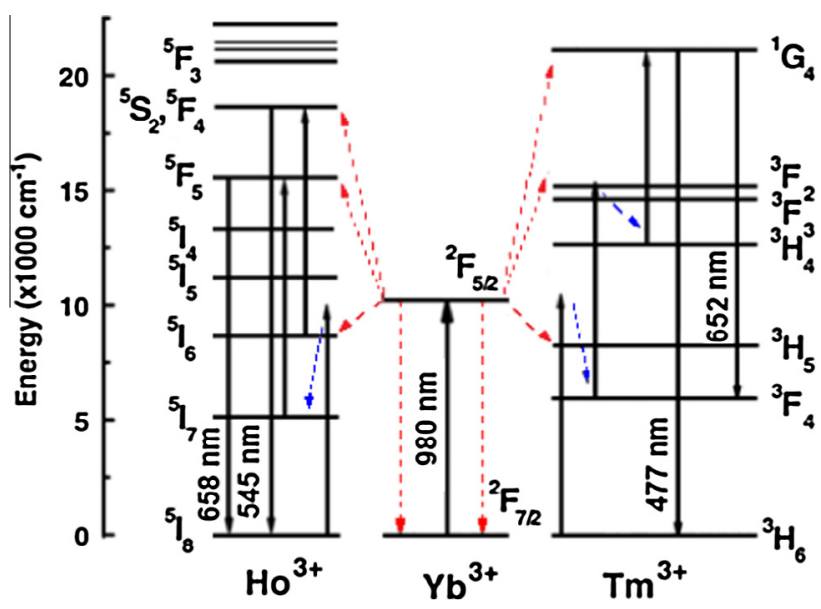

Fig. 4. Simplified energy level diagram of the $\mathrm{Ho}^{3+}, \mathrm{Tm}^{3+}$, and $\mathrm{Yb}^{3+}$ ions. The radiative transitions are indicated by solid lines. The energy transfer from $\mathrm{Yb}^{3+}$ to $\mathrm{Tm}^{3+}$ and $\mathrm{Ho}^{3+}$ are indicated by red dotted lines, and the phonon emissions are represented by blue dashed lines. (For interpretation of the references to color in this figure legend, the reader is referred to the web version of this article.)

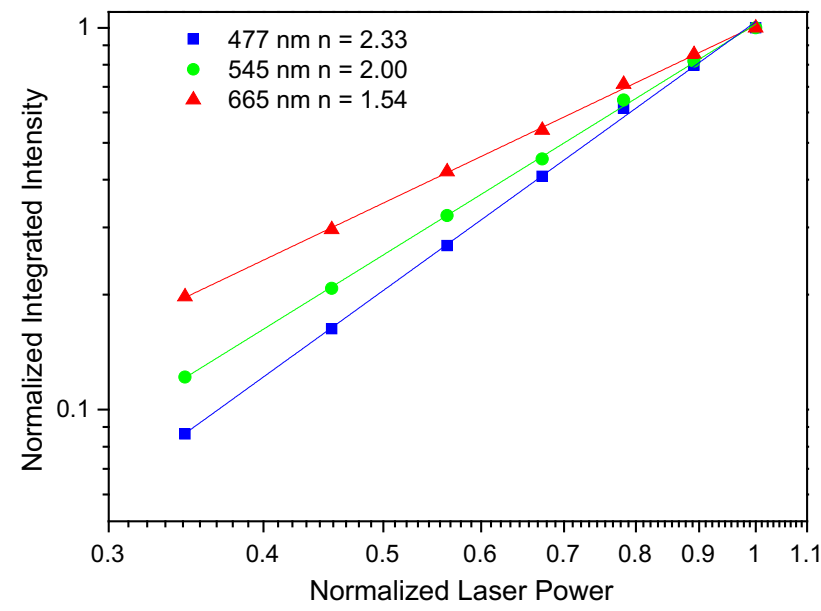

Fig. 5. Dependence of the upconversion intensity versus the laser power for the sample prepared with $1.0 \mathrm{wt} . \%$ of $\mathrm{AgNO}_{3}$ (sample B) that was heat treated during $24 \mathrm{~h}$.

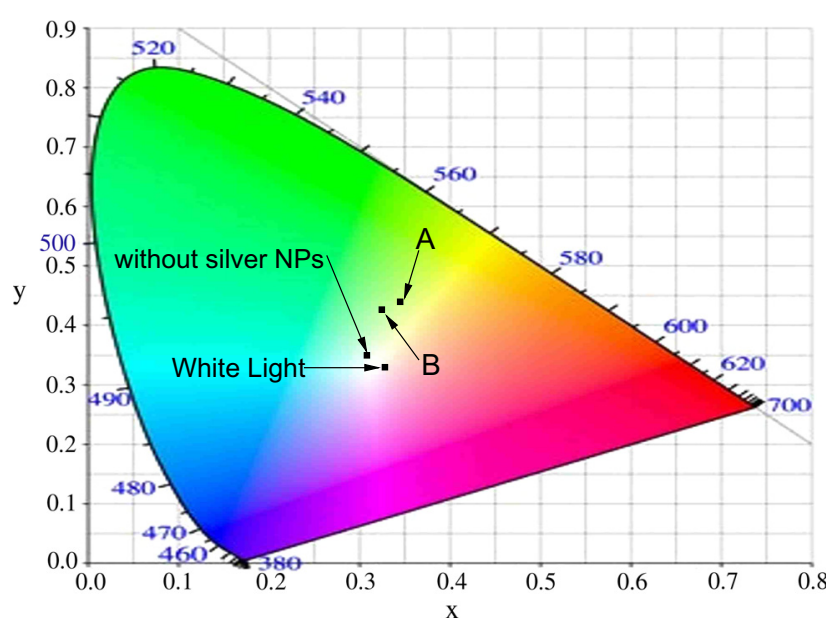

Fig. 6. $\mathrm{CIE}$ chromaticity diagram for the samples prepared with $1.0 \mathrm{wt} . \%$ of $\mathrm{AgNO}_{3}$ (samples A and B); the results for the samples without silver NPs are also shown.

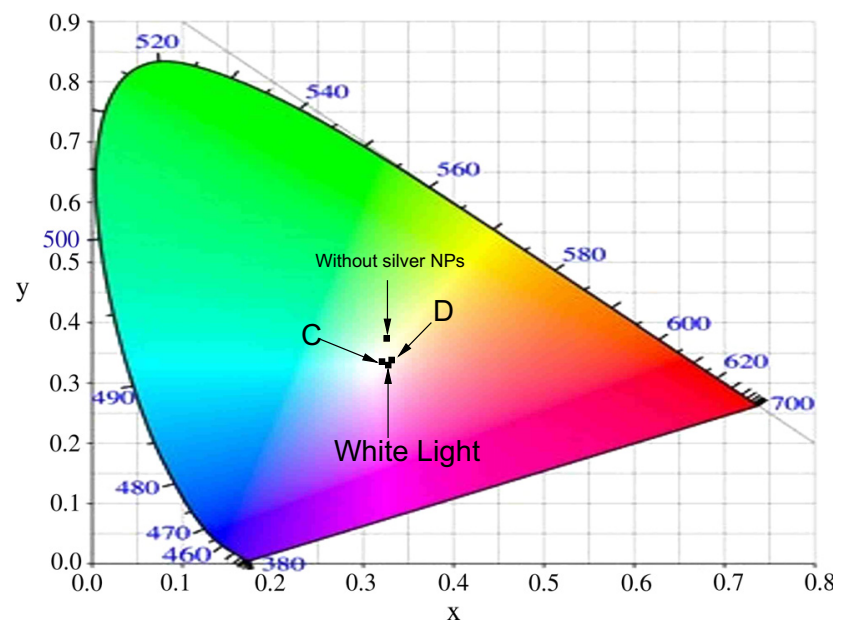

Fig. 7. CIE chromaticity diagram for the samples prepared with $2.5 \mathrm{wt}$.\% of $\mathrm{AgNO}_{3}$ (samples $\mathrm{C}$ and $\mathrm{D}$ ); the results for the samples without silver NPs are also shown.

calculated coordinates for the samples A and B are $(0.34 ; 0.44)$ and $(0.32 ; 0.42)$, respectively. We recall that the coordinates of the optimized sample produced without NPs $(0.31 ; 0.35)$ were 
already published in [13]. It can be seen that the coordinates for the samples produced with silver NPs are far from the white point $(0.33 ; 0.33)$. This effect is due to the fact that the PL transition $\left({ }^{5} \mathrm{~S}_{2}\right.$; $\left.{ }^{5} \mathrm{~F}_{4}\right) \rightarrow{ }^{5} \mathrm{I}_{8}$ is more affected than the other transitions by the presence of the silver NPs as evidenced by the $113 \%$ enhancement observed for the green intensity.

A different behavior was observed for the samples $C$ and $D$. For these samples the CIE coordinates presented in Fig. 7 are $(0.32$; $0.33),(0.33 ; 0.33)$ for samples with silver NPs and $(0.32 ; 0.37)$ for the sample without NPs. These results are correlated with Fig. 2 which shows that the blue and red emissions were enhanced by the nucleation of silver NPs whereas the green emission was quenched. The quenching of the green emission modifies the PL spectrum in a way that WLG was obtained.

\section{Conclusion}

This is the first report that shows the possibility of using silver NPs for controlling the color of germanate glass samples keeping fixed the rare-earth ions concentrations. The samples were prepared by the conventional melt-quenching method followed by heat-treatment. The samples' colors changed by selecting different heat-treatment time in order to change the amount of silver nanoparticles inside the samples. A remarkable result is the white light generation obtained with samples containing REI concentrations that were not adequate for this purpose if no silver NPs were present.

\section{Acknowledgements}

We acknowledge financial support by the Brazilian agencies Conselho Nacional de Desenvolvimento Científico e Tecnológico (CNPq) and Fundação de Amparo a Ciência e Tecnologia do Estado de Pernambuco (FACEPE). The work was performed in the framework of the National Institute of Photonics (INCT de Fotônica). We acknowledge the Nanotechnology National Laboratory (LNNano) for HR-TEM measurements.

\section{References}

[1] R. Vadrucci, C. Weder, Y.C. Simon, J. Mater. Chem. C 2 (2014) 2837-2841.

[2] Y.C. Simon, C. Weder, J. Mater. Chem. 22 (2012) 20817-20830.

[3] A. Monguzzi, F. Meinardi, J. Phys. Chem. A 118 (2014) 1439-1442.

[4] M. Haase, H. Scäfer, Angew. Chem. Int. Ed. 50 (2011) 5808-5829.

[5] F. Auzel, Chem. Rev. 104 (2004) 139-174.

[6] W. Xu, X. Min, X. Chen, Y. Zhu, P. Zhou, S. Cui, S. Xu, L. Tao, H. Song, Sci. Rep. 4 (2014) 5087

[7] J.W. Wang, A.T. Peter, J. Am. Chem. Soc. 132 (2010) 947-949.

[8] H. Gong, D. Yang, X. Zhao, E.Y.B. Pun, H. Lin, Opt. Mater. 32 (2010) 554-559.

[9] X. Liu, B. Chen, E.Y.B. Pun, H. Lin, C. Liu, J. Heo, Mater. Lett. 61 (2013) 3751 3754.

[10] D. Li, Y. Wang, X. Zhang, G. Shi, G. Liu, Y. Song, J. Alloys Comp. 550 (2013) 509513.

[11] L.X. Jun, H. Gong, B.J. Shen, H. Lin, E.Y.B. Pun, J. Appl. Phys. 105 (2009) 106109.

[12] N.Q. Wang, X. Zhao, C.M. Li, E.Y.B. Pun, H. Lin, J. Lumin. 130 (2010) 1044-1047.

[13] M.E. Camilo, E. de O. Silva, T.A.A. de Assumpção, L.R.P. Kassab, C.B. de Araújo, J. Appl. Phys. 114 (2013) 163515.

[14] L.R.P. Kassab, C.B. de Araújo, Germanate and tellurite glasses for photonic applications, in: V.P. Nilsson (Ed.), Photonics Research Developments, Nova Science Publishers Inc., New York, 2008. ISBN: 978-1-60436-720-5 (Chapter 13).

[15] T. Som, B. Karmakar, J. Opt. Soc. Am. B 26 (2009) B21-B27.

[16] S.K. Singh, N.K. Giri, D.K. Rai, S.B. Rai, Solid State Sci. 12 (2010) 1480-1483.

[17] V.A.G. Rivera, S.P.A. Osorio, D. Manzani, Y. Messaddeq, L.A.O. Nunes, E. Marega Opt. Mater. 33 (2011) 888-892.

[18] T.T. Sun, J. Lin, H.Y. Wei, Z.B. Feng, J. Inorg. Mater. 26 (2011) 1215-1220.

[19] T. Som, B. Karmakar, J. Alloys Comp. 509 (2011) 4999-5007.

[20] L.R.P. Kassab, D.S. da Silva, R.A. Pinto, C.B. de Araújo, Appl. Phys. Lett. 94 (2009) 101912.

[21] L.R.P. Kassab, D.S. da Silva, C.B. de Araújo, J. Appl. Phys. 107 (2010) 113506.

[22] T.A.A. de Assumpção, L.R.P. Kassab, A.S.L. Gomes, C.B. de Araújo, N.U. Wetter, Appl. Phys. B 103 (2011) 165-169.

[23] D.M. da Silva, L.R.P. Kassab, S.R. Luthi, C.B. de Araújo, A.S.L. Gomes, M.J.V. Bell, Appl. Phys. Lett. 90 (2007) 081913.

[24] L.R.P. Kassab, F.A. Bonfim, J.R. Martinelli, N.U. Wetter, J.J. Neto, C.B. de Araújo, Appl. Phys. B 94 (2009) 239-242.

[25] T.A.A. de Assumpção, D.M. da Silva, L.R.P. Kassab, C.B. de Araújo, J. Appl. Phys. 106 (2009) 063522

[26] M.E. Camilo, T.A.A. Assumpção, D.M. da Silva, D.S. da Silva, L.R.P. Kassab, C.B. de Araújo, J. Appl. Phys. 113 (2013) 153507.

[27] D.S. da Silva, T.A.A. de Assumpção, L.R.P. Kassab, C.B. de Araújo, J. Alloys Comp. 586 (2014) S516-S519.

[28] Y. Chiu, U. Rambabu, M.-H. Hsu, H.-P.D. Shieh, C.-Y. Chen, J. Appl. Phys. 94 (2003) 1996.

[29] A. Kipke, H. Hofmeister, Mater. Chem. Phys. 111 (2008) 254. 